\title{
CHARACTERIZATION OF SURFACE AND INTERNAL MOISTURE MIGRATION PROCESSES USING NONDESTRUCTIVE MEASUREMENT METHODS
}

Scientific paper

Maria Tunkiewicz

(Received: 14 October 2019; accepted: 16 June 2020)

University of Warmia and Mazury in Olsztyn, Faculty of Geoengineering, Institute of Geodesy and Civil Engineering, Department of General Construction and Building Physics, Poland, M.Sc.

Corresponding author: maria.tunkiewicz@uwm.edu.pl

\begin{abstract}
The proper choice of insulation materials contributes to the long and reliable operation of the envelope of a whole building. This paper presents the results of moisture-content determination in materials used for internal thermal insulation under different hygrothermal conditions. In this study, surface and internal moisture contents were measured. Moisture sensors that enable constant monitoring of material moisture content but with different operational characteristics, were used in the analysis. The operating principle of the first method involves the conversion of the amount of infrared radiation reflected in an electric signal, and the second method involves the analysis of the electric impulse propagation velocity. The measurement results of both methods are used to determine the drying-out characteristics of components used in internal thermal insulation and the sorptive properties of the selected materials. The results of comparative studies are also presented for these proposed methods as well as the gravimetric method to determine the usability of the proposed methods in determining the dampness level. The overall measurement results helped determine the relationship between the internal and surface moisture contents and the time needed for the moisture content in different parts of the selected materials to equalize.
\end{abstract}

Keywords: dampness; moisture content analyzer; time domain reflectometry; internal thermal insulation, nondestructive methods. 
Characterization of surface and internal moisture migration processes using nondestructive measurement methods

\section{INTRODUCTION}

The maintenance of historic buildings in satisfactory technical and operational conditions and the minimization of energy consumption has become a growing challenge. Legal requirements, the rising costs of heating and cooling of buildings, and the environmental care needed affect both users and administrators and require them to take measures aimed at reducing the energy consumption of buildings. A large number of buildings in Europe were constructed before the Second World War. Their partition walls are mostly made from bricks or stones and are characterized by a high value of the heat-transfer coefficient $\mathrm{U}$-value $\left[\mathrm{W} / \mathrm{m}^{2} \cdot \mathrm{K}\right]$. Another problem frequently associated with such facilities is an increased level of moisture content in the walls. This could result from various factors, including lashing rains, the failures of water supply and sewage systems, leaky roof sheathing, condensation, sorption, and the effects of groundwater in the absence of horizontal water insulation [1,2]. In addition, buildings from the aforementioned period and located within city centers (e.g., in old towns) are often characterized by skillfully made facade decorations, which are nowadays under preservation maintenance. Consequently, there is no possibility for tampering with the facade appearance. Therefore, the issue of improving thermal insulation of partition walls, including external thermal insulation of buildings, has become a challenge $[3,4]$.

Internal thermal insulations can make the building independent of external parameters, mainly temperature, without undesirable tampering of the external facade appearance. However, note that an increase in the thermalinsulation capability of a cross-section using materials that enhance the thermal resistance could result in interlaminar condensation, which causes hygrothermal changes in the building envelope [5]. The application of internal thermal insulation without prior heat and moisture analyses may result in considerable damage to the cross-section due to freeze-thawing $[6,7,8]$ as well as biological destruction $[9,10]$. The use of software to calculate heat and moisture transport is often helpful in such situations, although its verification in real conditions is of the greatest importance. The use of measurement equipment that provides reliable information about the moisture content in the cross-section and interface phenomena is important $[11,12,13]$. The moisture content within a cross-section can be determined by installing sensors during the construction of the cross-section or by using destructive methods $[14,15,16]$. The most common methods for measuring the moisture content include the gravimetric method; chemical methods, mostly the carbide method; electrical methods, mainly the microwave, dielectric, and resistance methods; nonelectrical methods, including the extraction, nuclear, and nuclear magnetic resonance methods; and methods based on the measurement of thermal properties. These methods have certain advantages and disadvantages. The main disadvantages of the above-mentioned methods include a high price, unavailability, discontinuous measurement, no possibility for real-time measurement, long measurement time, and the destructive nature of the method or a significant measurement error [17].

It is necessary to address the problem of moisture transfer in insulations from the inside, as this affects a large number of historic buildings. The main parameters that contribute to the reliable functioning, over many years, of a partition wall thermally insulated from the inside include the internal climate and relative humidity $(\mathrm{RH})$ prevailing in the premises; these are determined by the intended use of the room. Unfortunately, in north-eastern Poland, which is among the coldest regions in the world owing to the relatively severe and long winters, the issue of internal thermal insulation has not yet been resolved in a standardized manner [18,19].

This study aimed to establish the nature of drying-out and soaking of construction materials and components used as internal thermal-insulation systems. The first experimental stage involved the examination of materials from the wet to air-dry states, followed by the determination of the maximum adsorption of moisture from the environment in conditions generated by the climatic chamber. This paper also presents the usability of two uncommon moisture-content measurement methods: (1) a moisture content analyzer (MCA) with infra-red (IR) radiation, for contactless measurements of surface moisture content and (2) the method of electric impulse propagation using time-domain reflectometry (TDR), for monitoring the moisture content in construction materials on the phase boundary. The permanent monitoring of the mass movements within the cross-section is affected by the TDR method [20]. For several years, the TDR method was used to determine soil moisture [21,22]. Currently, it is used for measuring the moisture level of building materials in three kinds of mortar [23], red bricks [24], and porous materials $[25,26,27,28]$. The past decade has been a time of rapid developments in moisture analyzers that operate in the near-IR band. These devices continuously record and transmit the surface-moisture content. For years, the devices were only used in the paper industry to determine the moisture content in a moving paper 
ribbon $[29,30]$. However, these devices are now being used in several new applications. The benefits of their application in building construction include the possibility of long-term operation in elevated moisture and dust contents [31]. Some studies also verified two analyzed methods of moisture-content measurements under different boundary conditions.

To date, despite many studies conducted in this field, none focused on the simultaneous use of TDR and MCA to determine the moisture distribution and control the moisture-front movement in internal thermal insulations.

\section{MATERIALS AND METHODS}

For the study, three material samples were selected as part of the system solution, i.e., an adhesive layer, an insulation material, and a plaster coating including a layer of paint. The company that produces these materials declares that these are diffusion-open materials and they dry out owing to the movement of the moisture front from the wet side to the dry side; this occurs during the summer season. The first material was a light plaster coating used as an adhesive layer in internal thermal-insulation systems. It is particularly exposed to interlayer condensation if it is on the phase boundary between the masonry and thermal insulation material. Its features should include a short drying-out time and low moisture-accumulation rate. The second material was the ultralight autoclaved cellular concrete (ACC) with a bulk density of $115 \mathrm{~kg} / \mathrm{m}^{3}$. In the case of the occurrence of condensation, this material is directly exposed to excessive dampness. The considerable decrease in the most important material parameter, i.e., the thermal insulating power, is an important consequence of elevated dampness. The third material was a light mineral mortar coated with a paint layer of low diffusive resistance of $S d$ $=0.02[\mathrm{~m}]$. This material is directly exposed to the moisture in the room and should be resistant to excessive moisture absorption from the air. This feature is necessary to restrict the moisture flow from the room into the cross-section of the thermal insulation materials.

First, the material samples were prepared, as shown in Fig. 1. To avoid measurement errors in the TDR method, the samples shown in Figs. 1(b) and 1(c) were considered for investigation using this method: they were approximately 20-mm thick and 70-mm long. During the sample preparation, hygrometer sensors were embedded in the fresh compound, and after the compound hardened, the probe could be freely pulled out and reinserted. The samples were measured a month after their preparation to obtain a material with parameters equal to those to the material of the partition wall. Thus, the technological moisture was eliminated and the desired strength was obtained. Samples for which the MCA method was used had a flat surface (at least $30 \times 30 \mathrm{~mm}$ ), which is necessary to conduct measurements. Before the measurements, dust was removed from the samples by using a stream of compressed air. As shown in Fig. 1(a), the sample of ultra-lightweight gas concrete ACC S1-S3 was $70 \mathrm{~mm}$ in diameter and 20-mm thick, mortar MORT 1.1-1.3 and plaster coating CONGL 1.1-1.3 were rectangular prisms with dimensions of $45 \mathrm{~mm} \times 45 \mathrm{~mm} \times 8 \mathrm{~mm}$. Among these, the ultra-lightweight gas concrete samples were dry-cut-out using a metal bit, the material of which was sampled from the inside of the panel. The calibration curves were first prepared for each material type, following the guidelines of the device manufacturers. 
a

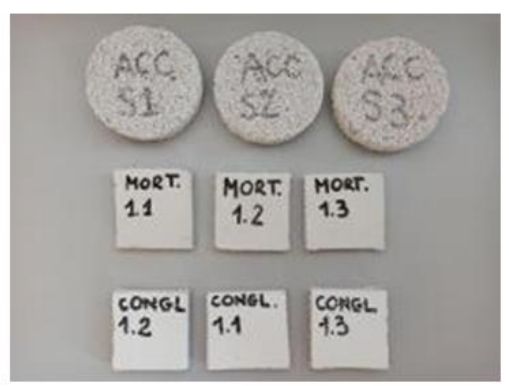

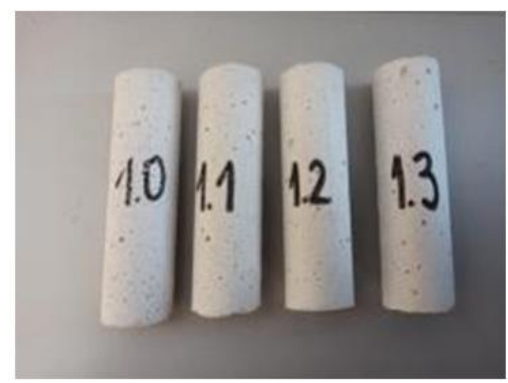

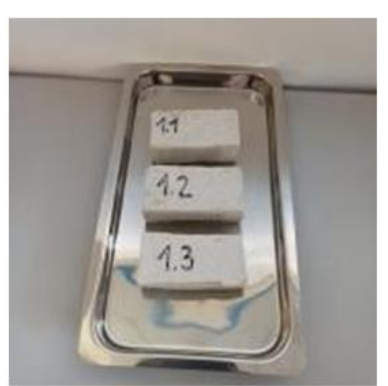

Figure 1 (a) Specimens used for the moisture-content analysis (MCA) and gravimetric method. (b) Specimens for time-domain reflectometry (TDR) and gravimetric method. (c) Specimens for the comparative analysis between the MCA and TDR methods.

\subsection{Operation of the moisture-content analyzer in the IR band}

The first device used in measurements was a contactless moisture-content analyzer, which uses reflected IR radiation to determine the moisture content in the material. The analyzer consists of three basic parts: the emitter that is responsible for the IR emission, a flexible fiber-optic cable called the probe, and a measuring device with computer software and a compatible moisture balance. The probe is made of 16 emitter and 16 receiver fibers. Here, lead sulfide $(\mathrm{PbS})$ acts as the photoresistor. The probe lights the surface under study with a beam of nearIR radiation. The wavelength generated by the device closely matches the $\mathrm{H}-\mathrm{O}-\mathrm{H}$ bond absorption parameters. The device emits a basic wavelength of $1.94 \mathrm{~mm}$, which is absorbed by water molecules with the greatest intensity [32]. The probe also emits IR radiation with a wavelength of 1.8 and $2.1 \mathrm{~mm}$. It is used for compression and ensuring that the measurement is independent of the texture or color of the surface under examination. The radiation that will not be absorbed is recorded by the sensor shown in Fig. 2.

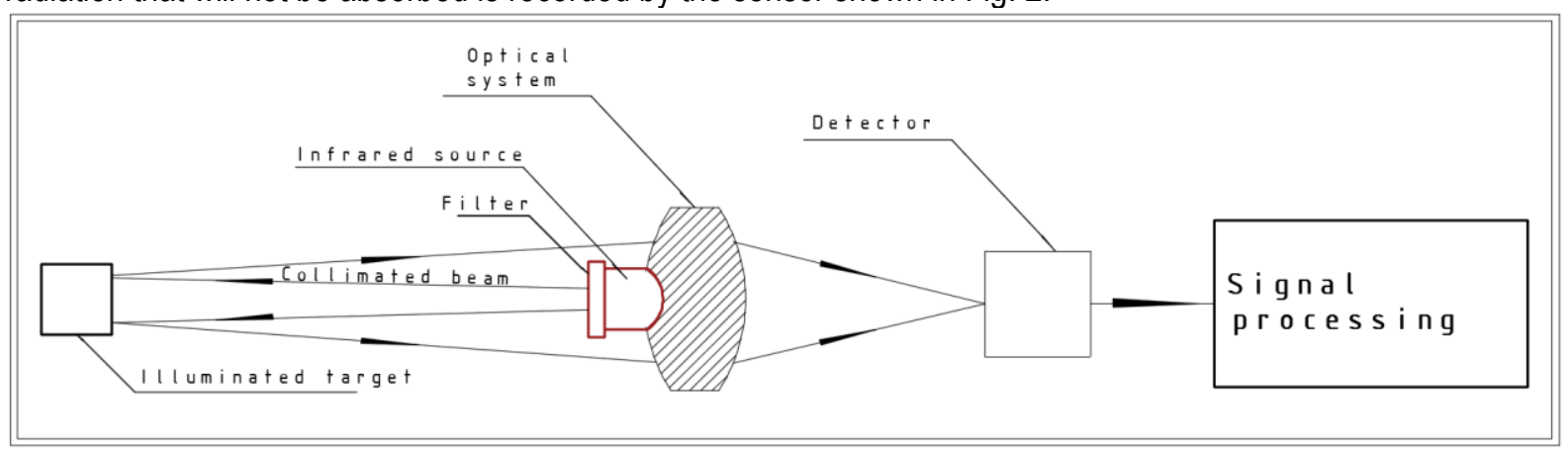

Figure 2 Components of the active IR system [33].

Information about the moisture content is obtained by the conversion of the reflected electromagnetic radiation to a recorded electric signal, which is displayed on the measuring device as voltage [mV] [34], according to the principle that the higher the material moisture content, the higher is the voltage. The calculations are based on the following formula:

$$
\text { Output }=C \cdot \log \left[E_{1800 \mathrm{~nm}}+E_{2100 \mathrm{~nm}} / 2 \cdot 1 / E_{1940 \mathrm{~nm}}\right]
$$

The moisture-content-measuring range of the device is $0 \%-60 \%(\mathrm{w} / \mathrm{w})$. The distance between the sensor and surface under examination was approximately $15 \mathrm{~mm}$. The penetration depth of the IR electromagnetic wave in this method was ca. $0.04 \mathrm{~mm}$ and it depends on the material's optical density [35,36]. A calibration curve must be developed for each type of tested material before the measurements are started. 
The relationship between the moisture content and voltage is determined through a calibrated drier with a socket for a sensor. The calibration process involves drying a wet sample and simultaneously measuring the voltage corresponding to the moisture content according to weight. During the drying process at the temperature set by the operator, breaks are programmed to cool down the sample, and only then is the moisture content measured using the probe.

\subsection{TDR-based moisture-content analyzer}

TDR-based moisture-content analyzers were the other devices used in the study measurements. A moisturecontent analyzer consists of probes, TDR/MUX/mpts, a measuring device, and compatible computer software. Up to eight probes can work simultaneously with the measuring device (the moisture content can be determined independently at eight points). The device principle of operation is based on the measurement of the tested material's electrical properties. The examination involves the determination of electromagnetic signal-propagation velocity in a wave-guide consisting of two metal rods. The metal rods exist in a probe and determine the time of impulse propagation, i.e., the higher the relative moisture content of the material, the higher is the signalpropagation velocity. The results are presented as percentage of moisture content, which is derived from the signal intensity. An individual measurement lasts approximately $1 \mathrm{~s}$, and the measurement result is depicted as a reflectogram. The points marked on the reflectogram determine the time interval, which is the basis for calculating the moisture content in a material.

The device was calibrated before the measurement, and the procedure included three basic elements: automatic verification of the length of the concentric cable between the TDR sensor and measuring device and the determination of the sensor's rod length and the so-called "dead time", i.e., the time during which an impulse travels twice between the time marker and beginning of the sensor electrodes [37].

\subsection{The measurement}

The surface moisture content was measured in a climatic chamber, as shown in Fig. 3, in which the predefined $\mathrm{RH}$ of air was generated. Each level of $\mathrm{RH}$ was maintained for two days, except that of $99 \%$, which was maintained until the sample weight was stabilized. Initially, measurements were obtained using samples dried at $105{ }^{\circ} \mathrm{C}$ from RH of $20 \%$. The temperature in the climatic chamber was stable at a level of $23 \pm 0.5{ }^{\circ} \mathrm{C}$. Subsequently, the $\mathrm{RH}$ of air in the chamber was increased and the moisture content in the material was measured. Each test involved reading the moisture content by using a contactless IR analyzer and weighing by using a precision balance with an accuracy of $1 / 10,000 \mathrm{~g}^{-1}$. It is noteworthy that the measuring sensor was fixed permanently in the climatic chamber. The samples were always weighed outside the chamber after their moisture content was determined using the sensor. 


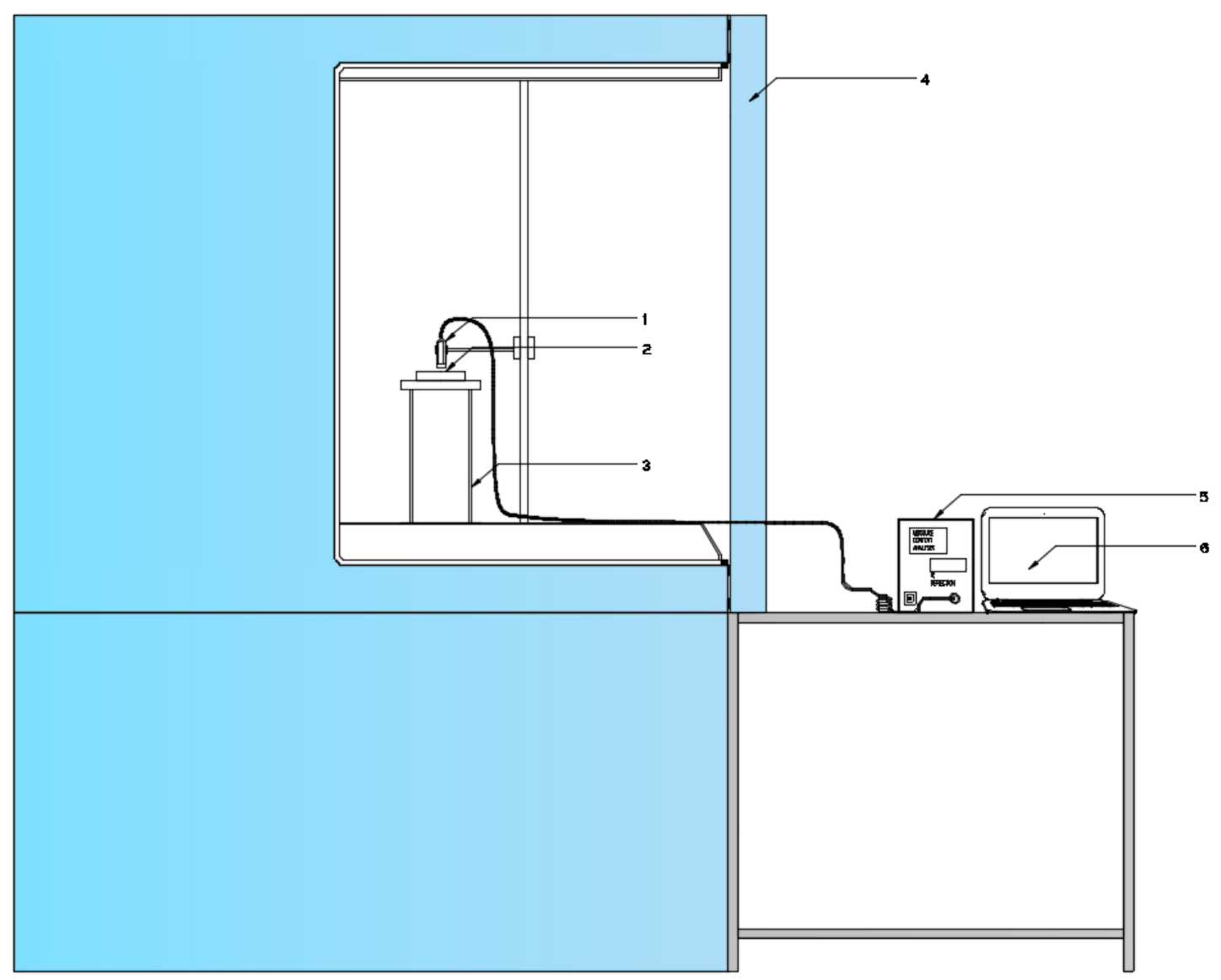

Figure 3 Diagram of the climatic chamber using in the study, where 1. IR probe of the moisture-content sensor; 2. tested sample; 3. sample base; 4. climatic chamber; 5. moisture content analyzer (MCA); 6. computer.

Subsequently, the internal moisture content of the insulation-system materials was determined using the TDR. The measurements included those of the material when dried using the drying-out process as well as those obtained after it was completely soaked in water until its air-dry state. The results were verified using the gravimetric method. The measurements involved the monitoring of the drying-out rate of the adhesive mortar. The experiment was conducted on cylinders to ensure a sufficiently thick wrap around the wave guide. Mature, wellformed samples were immersed in water to make them as moist as possible. They were then pulled out, and the recording of the drying-out process was started. The decrease in the sample weight was monitored twice daily during the initial period of five days and once daily afterward. The balance used for the measurements had an accuracy of $1 / 1000 \mathrm{~g}$.

These experiments helped determine the relationship between the internal and surface moisture contents and the time taken for the moisture content in different parts of the materials under study to equalize by the two aforementioned methods. The samples were soaked in water before the measurements. 


\section{RESULTS}

\subsection{Results of the MCA method}

The measurement results are shown in Figs. 4-6. Figures 4 (a), 5 (a), and 6 (a) show the relationship between the weight-based and surface moisture contents at different levels of relative air humidity in the range of $0 \%-99$ $\%$. Figures $4(\mathrm{~b}), 5(\mathrm{~b})$, and $6(\mathrm{~b})$ show the enlarged views of the moisture characteristics of the samples in the range of $90 \%-99 \%$. Figure 4 shows the characteristics of ultralight ACC. The results labeled as ACC along with a sample number were obtained from measurements with a balance, whereas those marked as ACC MCA were obtained through the moisture-content analyzer.
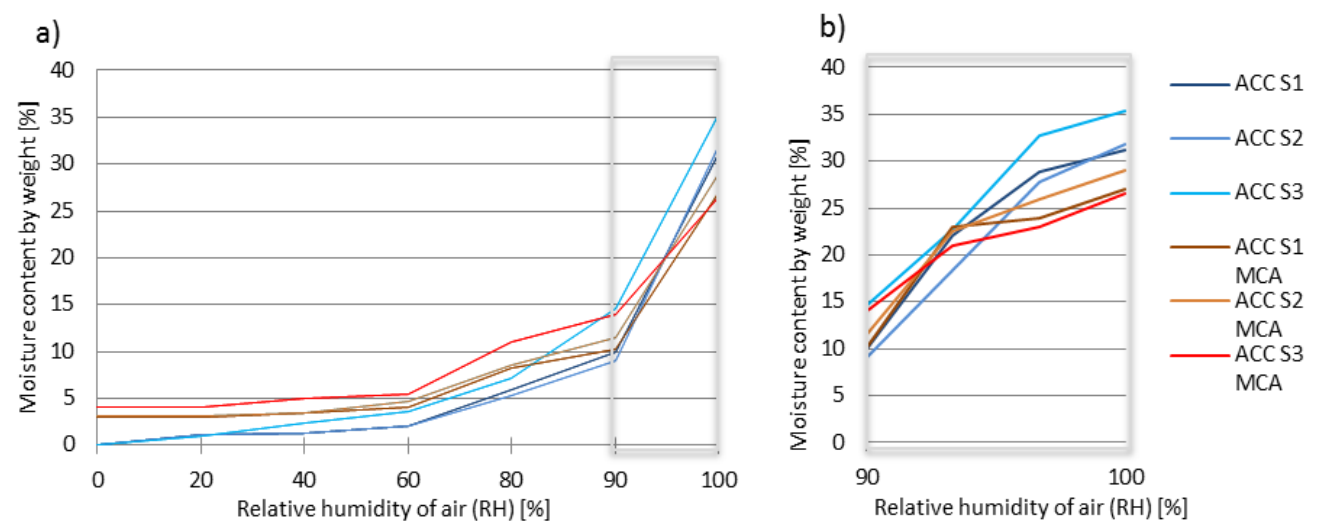

Figure 4 Sorptive properties of ultralight autoclaved cellular concrete; comparison between the MCA and gravimetric methods

Figure 5 shows the characteristics for the adhesive mortar with a layer of paint open to diffusion. The results marked as CONGL along with a sample number were obtained from measurements using a balance, whereas those marked as CONGL MCA were obtained using a surface-moisture analyzer.

a)



b)



Figure 5 Comparative analysis of the sorptive properties of adhesive mortar covered with a paint coat obtained using the MCA and gravimetric methods.

Figure 6 shows the characteristics of the adhesive mortar alone. The results marked with MORT with a sample number were obtained from measurements with a balance, whereas those marked MORT MCA were obtained using measurements from a moisture analyzer. 
Characterization of surface and internal moisture migration processes using nondestructive measurement methods
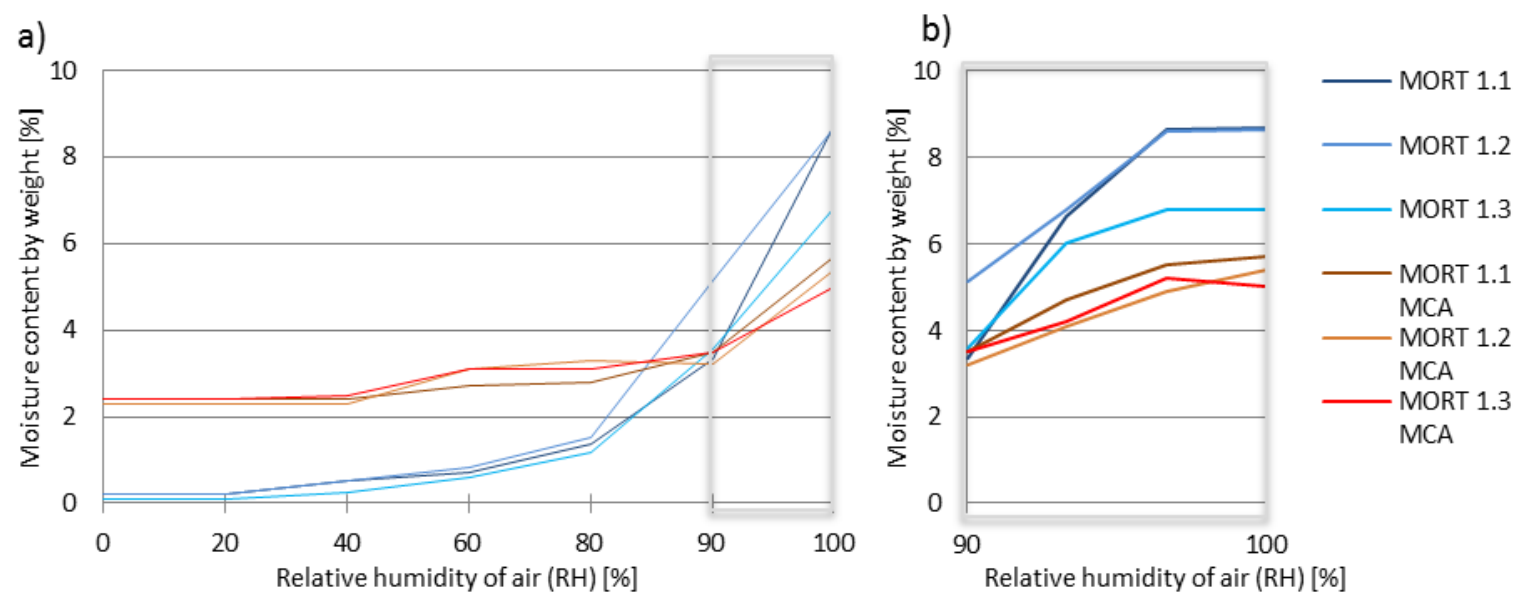

Figure 6 Comparative analysis of sorptive properties of light mineral mortar obtained using the MCA and gravimetric methods

\subsection{Results obtained using the TDR method}

Figures 7 and 8 show the process of the drying out of the material from its completely soaked state to its air-dried state. The tests were performed only for the samples of adhesive mortar. Figure 7 shows the results for the TDR and gravimetric methods, and Figure 8 shows the constant monitoring results for the samples of adhesive mortar by using the MCA method. The green, red, and blue curves represent the results obtained using the TDR, MCA, and

gravimetric

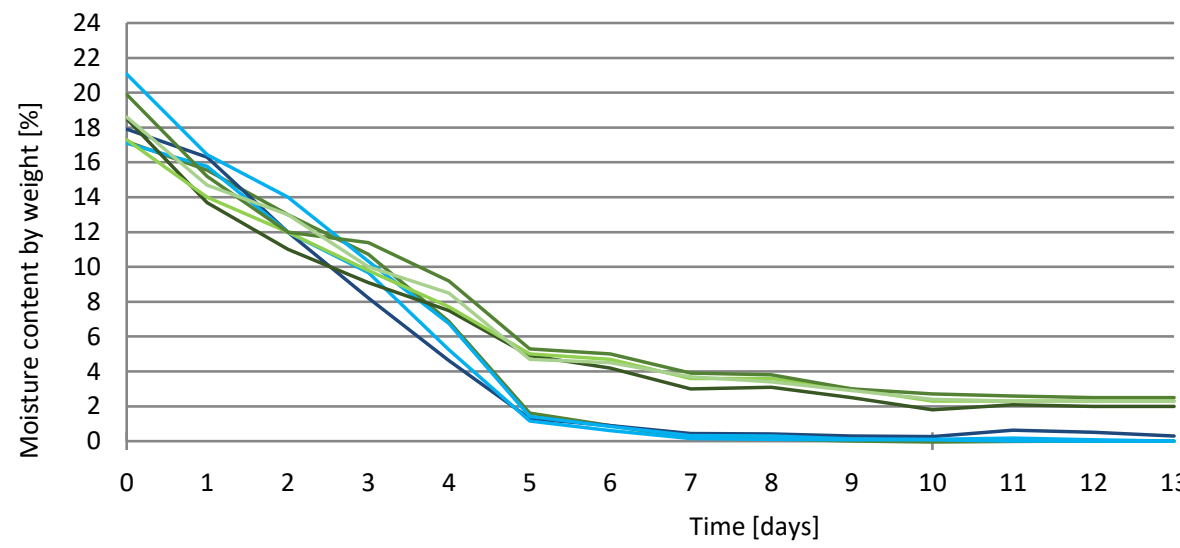

respectively.

Figure 7 Results of moisture according to weight obtained using TDR and gravimetric methods; adhesive mortar drying-out process

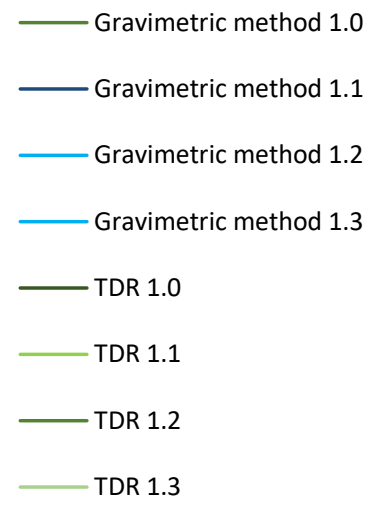

Tunkiewicz, M 


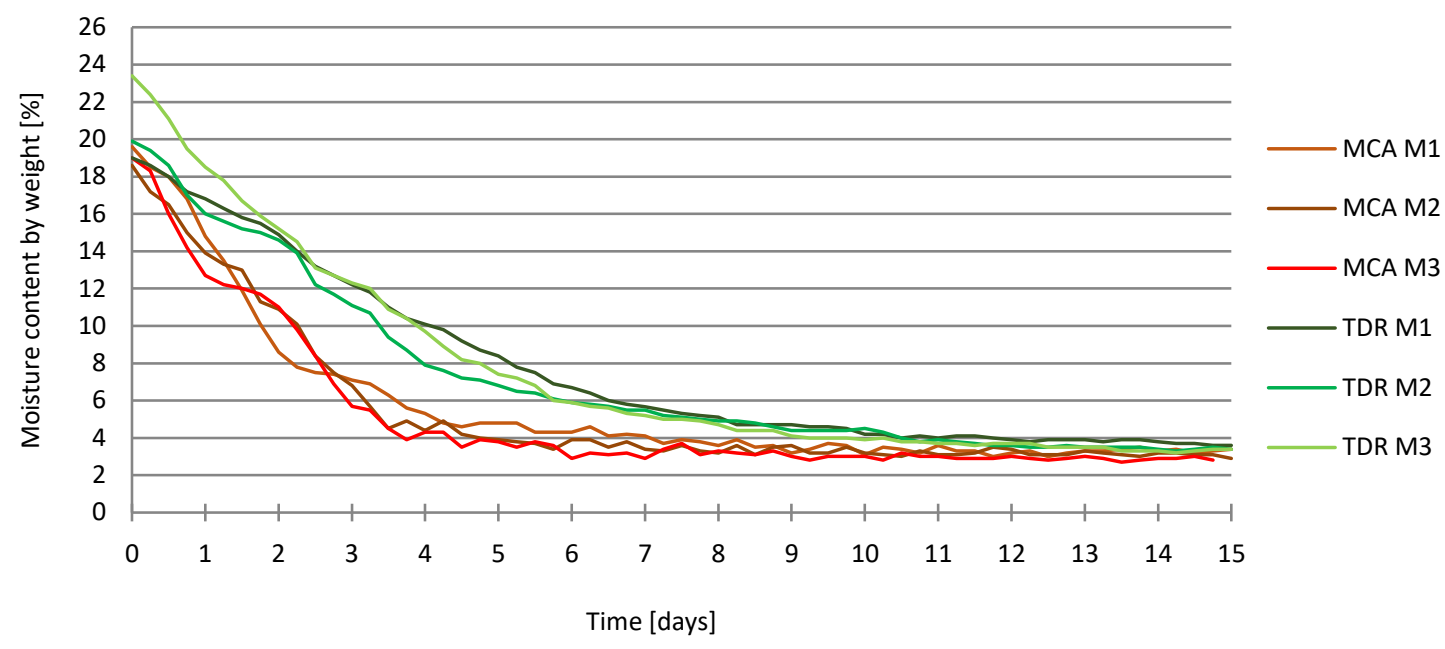

Figure 8 Adhesive mortar drying-out process; Comparative results of TDR and MCA methods

\section{DISCUSSION}

The results showed that the surface moisture content in the MCA method is usually lower than that of the gravimetric method at the highest air RH levels. Therefore, the measurement results are considered to be affected by high air humidity as well as individual characteristics of moisture redistribution and certain limitations of the device measuring capabilities. The results in Figs. 4 (a), 5 (a), and 6 (a) are similar in other aspects. The maximum material-dependent dampness accounts for up to $35 \%$ of the weight-based moisture content for the gravimetric method and up to $30 \%$ of surface moisture content for the MCA method for ultralight ACC (Figs. 4 (b) and 6 (b)). The weight-based and surface moisture contents for the adhesive mortar with a paint coat are 8\%$10 \%$. The defined values of sorption isotherms have a similar course to results of studies using the gravimetric method [38, 39].

Figure 6 (b) shows that the maximum moisture content detected by the TDR sensor for the adhesive mortar is $24 \%$; the results for the gravimetric method were similar. The greatest differences between these methods appear in the range of $10 \%-2 \%$. The curves determined using the TDR method are gentler, and in about 10 days, according to indications of this method, the samples dry out. It is noteworthy that the surface moisture content shown in Figure 4 (b) at the state of the highest moisture content accounts for nearly $50 \%$ of the material's weight-based moisture content with the complete sample immersion in water. The measured values do not differ from the calibration curves for other materials determined using this method, e.g., frozen soil $[40,41]$ or aerated concrete [26].

Figure 7 shows the results of moisture content measured using the MCA and TDR methods. The graph shows consistent information, i.e., the internal moisture content measured using the TDR method is slightly higher than the surface moisture content measured using the MCA method. The initial moisture content is $19 \%-26 \%$ for the TDR method and $17.5 \%-19.5 \%$ for the MCA method. The greatest differences were observed within the range of $6 \%-15 \%$ for the weight-based moisture content; this difference is undoubtedly associated with the drying-out characteristics of the material and the surface drying-out rate.

\section{CONCLUSION}

The following conclusions can be drawn according to the study results.

- Based on the measured values and literature reports including for the calibration curves of various materials, the TDR method can be concluded to be reliable tool for determining the dynamics of moisture changes in the tested materials. The method can also be used to determine the moisture content of internal thermal-insulation systems including ultralight ACC and adhesive system mortar. 
- Based on the experimental results, the methods under analysis that enable the constant monitoring of moisture redistribution provide satisfactory results for the determination of surface and internal moisture contents with respect to the results obtained using the gravimetric method. Note that surface or internal moisture content is not equivalent to the material's weight-based moisture content. According to Refs. [42, 43], chemically bound water is not considered in the gravimetric method as a dampness level. In contrast, the methods based on the absorption of IR radiation or electromagnetic-wave redistribution velocity consider all kinds of water molecule bonds in the material, including chemical bonds. This results in elevated moisture content in the dry material. Both methods indicate $2 \%$ mass-based moisture content for the dry material.

- The covering of the sample's surface with open-diffusion paint has minimal impact on the determination of sorption isotherms measured using the gravimetric method; the difference is about $1 \%$. In contrast, the MCA device shows differences up to $5 \%$. Note that in devices that use IR radiation for measurements, the accurate calibration of the device in advance is very important; this can significantly reduce the measurement error.

- Gravimetric mass inspection is still an important element in all the measurements; it allows verification of the tested measurement methods: TDR and MCA. Despite the differences, the calibration curves obtained using the gravimetric method were always close to the humidity values measured using nondestructive methods.

- The experiments give rise to further considerations concerning the usability of the devices for monitoring surface and internal water content in the cross-section. They provide knowledge about measurements of moisture redistribution in layers of internal thermal insulation without destroying the cross-section while remaining compact and usable in nearly all conditions. They enable timely moisture-content monitoring, observation of vapor condensation in the interlayer space, and observation of the material drying-out front movement. The observed differences between the methods show their different operational modes. The determination of moisture content using the MCA and TDR methods gives equally satisfactory results with differences in humidity of about $5 \%$ in a short time interval. In subsequent future tests, the thickness of the material being tested should be kept to a minimum to minimize the error resulting from it. In contrast, tests could be conducted in such a way as to determine moisture according to material thickness (not only in the sample core).

- According to the author, these methods can be used for measurements on materials similar in composition and application and that provide reliable results.

\section{References}

[1] Rosłon, J.; Seroka, M. 2016: Multicriteria Selection of Water Insulation Technology for Foundation Walls in an Existing Building, Archives of Civil Engineering, 62 (3), pp. 167-176. https://doi.org/10.1515/ace-2015$\underline{0090}$

[2] Straube, J.; Schumacher, C. 2007: Interior Insulation Retrofits of Load-Bearing Masonry Walls in Cold Climates, Journal of Green Building, 2 (2), pp. 42-50. https://doi.org/10.3992/jgb.2.2.42

[3] Walker, R.; Pavía, S. 2015: Thermal performance of a selection of insulation materials suitable for historic buildings, Building and Environment, 94, pp. 155-165. https://doi.org/10.1016/i.buildenv.2015.07.033

[4] Martínez-Molina, A.; Tort-Ausina, I.; Choc, S.; Vivancos, J.L. 2016: Energy efficiency and thermal comfort in historic buildings: A review, Renewable and Sustainable Energy Reviews, 61, pp. 70-85. https://doi.org/10.1016/i.rser.2016.03.018

[5] Wójcik, R.; Kosiński, P. 2017: On rehabilitation of buildings with historical facades, Energy Procedia, 132, pp. 927-932. https://doi.org/10.1016/i.egypro.2017.09.724 
Characterization of surface and internal moisture migration processes using nondestructive measurement methods

[6] Zhou, X.; Carmeliet, J.; Derome, D. 2020: Assessment of risk of freeze-thaw damage in internally insulated masonry in a changing climate, Building and Environment, 175, https://doi.org/10.1016/i.buildenv.2020.106773

[7] Zhou, X.; Derome, D.; Carmeliet, J. 2017: Hygrothermal modeling and evaluation of freeze-thaw damage risk of masonry walls retrofitted with internal insulation, Building and Environment, 125, pp. 286-298. https://doi.org/10.1016/j.buildenv.2017.08.001

[8] Wojcik, R.; Bomberg, M. 2016: On interior rehabilitation of buildings with historic facades, Journal of Building Physics, 40 (2), pp.144-161. https://doi.org/10.1177/1744259116662280

[9] Harrestrup, M.; Svendsen, S. 2016: Internal insulation applied in heritage multi-storey buildings with wooden beams embedded in solid masonry brick façades, Building and Environment, 99. pp. 59-72. http://dx.doi.org/10.1016/i.buildenv.2016.01.019

[10] Isaksson, T.; Thelandersson S.; Ekstrand - Tobin A.; Johansson P. 2010: Critical conditions for onset of mould growth under varying climate conditions, Building and Environment, 45 (7), pp. 1712-1721. https://doi.org/10.1016/.buildenv.2010.01.023

[11] Nagy, B. 2019: Designing insulation filled masonry blocks against hygrothermal deterioration, Engineering Failure Analysis, 103, pp.144-157. https://doi.org/10.1016/j.engfailanal.2019.05.005

[12] Manzan, M.; De Zorzi, E.Z.; Lorenzi, W. 2015: Experimental and Numerical Comparison of Internal Insulation Systems for Building Refurbishment, Energy Procedia, 82, pp. 493-498. https://doi.org/10.1016/i.egypro.2015.11.853

[13] Zhao, J.; Plaffe, R.; Grunewald, J. 2011: Performance assessment of interior insulations by a stochastic method, In 9th Nordic Symposium on Building Physics-NSB 2011, 1, pp. 465-472.

[14] Nagy, B.; Szagri D.; Bakonyi D. 2019: Hygrothermal Analysis of Mineral Wool Insulated Building Constructions Based on In Situ Measurements, Applied Mechanics and Materials, 887, pp. 605-612. https://doi.org/10.4028/www.scientific.net/AMM.887.605

[15] Nilsson, L.-O. Ed. 2018: Methods of Measuring Moisture in Building Materials and Structures. Springer International Publishing.

[16] Phillipson, M.C.; Baker, P.H.; Davies, M.; Ye, Z.; McNaughtan, A.; Galbraith, G.H.; McLean, R.C. 2007: Moisture measurement in building materials: an overview of current methods and new approaches, Building Serv Eng Res Technol, 28 (4), pp. 303-316. https://doi.org/10.1177/0143624407084184

[17] Kamiński, K. 2008: Low usefulness of electric moisture meters to estimate dampness of ceramic brick walls, Inżynieria i Budownictwo, pp. 188-192. (in Polish)

[18] Ustrnul, Z.; Czekierda, D.; Wypych, A. 2010: Extreme values of air temperature in Poland according to different atmospheric circulation classifications, Physics and Chemistry of the Earth, Parts A/B/C, 35 (9-12), pp. 429-436. https://doi.org/10.1016/j.pce.2009.12.012

[19] Wibig, J.; Glowicki B. 2002: Trends of minimum and maximum temperature in Poland, Climate Research 20 (2), pp. 123-133. https://doi.org/10.3354/cr020123

[20] Suchorab, Z., 2016: Zastosowanie techniki reflektometrii w domenie czasu do oceny stanu zawilgocenia przegród budowlanych, Monografie Komitetu Inżynierii Środowiska PAN, 133 ISBN: 978-83-63714-32-1 (in Polish)

[21] Topp, G.C.; Reynolds, W.D. 1998: Time domain reflectometry: a seminal technique for measuring mass and energy in soil, Soil Till. Res., 47 (1-2), pp. 125-132. https://doi.org/10.1016/S0167-1987(98)00083-X

[22] Skierucha, W.; Wilczek, A.; Alokhina, O. 2008: Calibration of a TDR probe for low soil water content measurements, Sens. Actuators A, 147 (2), pp. 544-552. https://doi.org/10.1016/j.sna.2008.06.015

[23] Agliata, R.; Mollo, L.; Greco, R. 2016: Use of TDR to compare rising damp in three tuff walls made with different mortars, Journal of Materials in Civil Engineering, 29 (4). https://doi.org/10.1061/(ASCE)MT.19435533.0001794

[24] Suchorab, Z. 2013: Laboratory measurements of moisture in a model red-brick wall using the surface TDR probe, Proceedings of ECOpole, 7 (1), pp. 171-176. https://doi.org/10.2429/proc.2013.7(1)022

[25] Černý, R. 2009: Time-domain reflectometry method and its application for measuring moisture content in porous materials: a review, Measurement, $42 \quad$ (3), pp. $329-336$ https://doi.org/10.1016/..measurement.2008.08.011 
[26] Sobczuk, H.; Suchorab, Z. 2005: Calibration of TDR instruments for moisture measurement of aerated concrete, Monitoring And Modelling the properties of soil as porous medium, Institute of Agrophysics Polish Academy of Sciences, pp. 158-165, ISBN 83-87385-95-6.

[27] Suchorab, Z.; Widomski, M.; Łagód, G.; Sobczuk, H. 2010: Capillary rise phenomenon in aerated concrete, Monitoring and simulations, Proceedings of ECOpole, 4 (2), pp. 285-290.

[28] Suchorab, Z. 2014: Monitoring of capillary rise phenomenon in calcium silicate board using the surface TDR probes set, Proceedings of ECOpole, 8 (1), pp. 82-86. https://doi.org/10.2429/proc.2014.8(1)010

[29] Sawoszczuk, T.; Barański, A.; Łagan, J.M.; Łojewski,T.; Zięba, K. 2008: On the use of ASTM closed vessel tests in accelerated ageing research, Journal of Cultural Heritage, 9 (4), pp. 401-411. https://doi.org/10.1016/i.culher.2007.10.010

[30] Larsson, P. A.; Wagberg, L. 2009: A novel approach to study the hydroexpansion mechanisms of paper using spray technique, Nordic Pulp and Paper Research Journal, 24 (4), pp. 371-380. https://doi.org/10.3183/NPPRJ-2009-24-04-p371-380

[31] Hall, P. 1993: Practical Paper - Machine Wet - End Diagnostics, World Pulp Paper Technology, pp. 201205.

[32] Burns, D. A., Ciurczak, E. W. 1992: Handbook of near - infrared analysis, New York: Marcel Dekker, ISBN: 978-08-49373-93-0

[33] Hackforth, H. L. 1960: Infrared radiation, New York: McGraw Hill Book Company, ISBN-10: 1258246074

[34] Larsson, P. A. 2010: Hygro-and hydroexpansion of paper: influence of fibre-joint formation and fibre sorptivity (Doctoral dissertation, KTH).

[35] Wójcik, R.; Tunkiewicz, M. 2017: Non-contact method of measuring moisture transport in plaster mortars with the use of NIR radiation, Materiały Budowlane, http://dx.doi.org/10.15199\%2F33.2017.03.08 (in Polish)

[36] Bostrom, Bernt; Fibro System AB. Measurement of Dynamic Moisture Gradients in the z - direction.

[37] Instrukcja obsługi FOM/mts i TDR/MUX/mpts Wersja 1.3. [Operation manual for $F O M / m t s$ and TDR/MUX/mpts, Version 1.3.] (2010). Lublin: Instytut Agrofizyki Polska Akademia Nauk. (in Polish)

[38] Jerman, M.; Černý, R. 2012: Effect of moisture content on heat and moisture transport and storage properties of thermal insulation materials, Energy and Buildings, 53, pp. 39-46 https://doi.org/10.1016/i.enbuild.2012.07.002

[39] Zhao, J.; Grunewald, J.; Ruisinger, U.; Feng, S. 2017: Evaluation of capillary-active mineral insulation systems for interior retrofit solution, Building and Environment, 115, pp. 215-227. https://doi.org/10.1016/.buildenv.2017.01.004

[40] Xiaohai, Z.; Jian, Z.; Wolfgang, K.; Fritz, S. 2017: Simultaneous measurement of unfrozen water content and ice content in frozen soil using gamma ray attenuation and TDR, 50 (12), pp. 9630-9655. https://doi.org/10.1002/2014WR015640

[41] Malicki, M. A.; Plagge, R.; Roth, C. H. 1996: Improving the calibration of dielectric TDR soil moisture determination taking into account the solid soil, European Journal of Soil Science, 47 (3), pp. 357-366. https://doi.org/10.1111/j.1365-2389.1996.tb01409.x

[42] Trochonowicz, M. 2010: Moisture in buildings objects. Humidity testing problems, Budownictwo i Architektura, 7, pp.131-144. (in Polish)

[43] Wójcik R. 2002: Pomiary wilgotności przegród budowlanych, Materiały Budowlane, 8, pp. $42-43$ (in Polish)

Please cite this article as: Tunkiewicz, M.: Characterization of surface and internal moisture migration processes using nondestructive measurement methods, Electronic Journal of the Faculty of Civil Engineering Osijek-eGFOS, 2020, 20, pp. 51-62, https://doi.org/10.13167/2020.20.5 